\title{
Identidade surda e intervenções em saúde na perspectiva de uma comunidade usuária de língua de sinais
}

\author{
Identity of the deaf and interventions in health \\ from the perspective of a community of sign language users
}

Juliana Donato Nóbrega ${ }^{1}$

Andréa Batista de Andrade ${ }^{1}$

Ricardo José Soares Pontes ${ }^{1}$

Maria Lúcia Magalhães Bosi ${ }^{1}$

Márcia Maria Tavares Machado ${ }^{1}$

\footnotetext{
${ }^{1}$ Programa de Pós-

Graduação em Saúde

Coletiva, Departamento de

Saúde Comunitária,

Faculdade de Medicina,

Universidade Federal do

Ceará. Rua Professor Costa

Mendes 1608, Rodolfo

Teófilo. 60430-140

Fortaleza CE.

julianadonato7@yahoo.com.br
}

\begin{abstract}
The biomedical view sees deafness as a physiological loss of audition and the deaf as individuals with an organic abnormality to be corrected; healthcare interventions support this perception. This study sought to understand deafness from the standpoint of the deaf, in order to identify elements for public policies addressed to them in the context of the ethical dimension of care. The research adopted the qualitative approach (focus groups) and 9 members of a deaf community in Fortaleza (Ceará-Brazil), all fluent in Brazilian Sign Language-LIBRAS, took part. The results show deafness is perceived as a way of being based on day-to-day experiences of visual interaction with nature and society, giving the deaf a different identity in terms of culture (being deaf) and linguistics (LIBRAS). Some public policies for oral training and technological interventions, like cochlear implants, are seen as a setback by the deaf, as it negates their status in the world and involves a loss of identity for the deaf. It is necessary to consider the deaf from a socio-historic, symbolic and cultural standpoint where different discourses co-exist, over and above the physiological dimension.
\end{abstract}

Key words Deafness, Identity, Deaf culture, Health
Resumo A visão biomédica concebe a surdez como perda fisiológica da audição e o surdo como portador de anomalia orgânica a ser corrigida; intervenções de saúde revestem-se, correspondentemente, de tal representação. Objetivamos compreender as representações sobre surdez entre surdos, com o propósito de refletir sobre políticas públicas a eles destinadas no contexto da dimensão ética do cuidado. Utilizamos o referencial teórico-metodológico qualitativo (grupo focal); participaram 9 membros de uma comunidade surda (Fortaleza-CE, 2010) fluentes na Língua Brasileira de Sinais-Libras. Observamos que a surdezé compreendida como um modo de ser, cotidianamente construído, essencialmente a partir das experiências-vivências de interação visual com a natureza e a sociedade; assume caráter identitário particular, afirmado em componentes culturais (ser surdo) e linguísticos (Libras). Políticas públicas de oralização ou tecnologias auditivas corretivas (como o implante coclear), valorizados pela sociedade ouvinte, são representadas como retrocesso nas lutas dos surdos, de negação de seu ser no mundo e como perda da identidade surda. É necessário compreender o surdo a partir de construções histórico-sociais, simbólicas e culturais onde diferentes discursos co-existem, para além da dimensão fisiológica.

Palavras-chave Surdez, Identidade, Cultura surda, Saúde 


\section{Introdução}

Tradicionalmente, a pessoa com surdez é concebida como um ser inferior, não raro considerada anormal, dependente de outras pessoas e incapaz de se prover $^{1}$. Ainda na antiguidade clássica, Aristóteles considerava ser a linguagem o veículo que possibilitava a própria condição de humano. Assim, o nascido surdo, por não falar nem possuir linguagem, não raciocinava ${ }^{2}$.

Com o advento da ciência moderna instituiuse o paradigma biomédico como discurso hegemônico sobre a surdez e o surdo no domínio da saúde, particularmente nas esferas técnico-científica e profissional. O surdo tornou-se objeto de pesquisa das ciências da saúde e a surdez passou a ser vista sob o ponto de vista orgânico-biológico, classificada em diferentes graus de (in) capacidade de audição ${ }^{3}$.

A representação da normalidade/anormalidade cunhada pelo saber científico concebeu a surdez e o surdo tão somente como objeto da ciência e dos especialistas, detentores da qualificação e do mandato para descrever, classificar e intervir no chamado paciente surdo ${ }^{3-5}$.

Neste contexto, pessoas com surdez passaram a ser denominadas deficientes auditivas, $e$, por extensão, representadas, elas mesmas, em sua integralidade humana, como deficientes ${ }^{6,7}$. Consolidou-se então uma perspectiva de intervenção oralista em relação aos surdos. No século XIX, no Congresso de Milão, foi estabelecida como norma a superioridade da fala em detrimento de outras formas de comunicação do surdo, tal como a língua de sinais ${ }^{8}$

Ao longo do século XX, o oralismo foi reafirmado a partir do aperfeiçoamento progressivo das tecnologias auditivas corretivas, com a premissa subjacente de que a estimulação auditiva possibilitaria ao surdo/deficiente auditivo se comunicar por meio da terapia da fala ${ }^{2,5}$.

Mais recentemente, impulsionados pelas invenções tecnológicas e pela perspectiva de transformar o surdo em ouvinte, mediante a recuperação da audição, vários artefatos auditivos vêm sendo desenvolvidos, particularmente o implante coclear, que tem sido considerado pela comunidade técnico-profissional como terapia curativa da surdez. As políticas públicas voltadas ao surdo no Brasil, como a Política Nacional de Atenção à Saúde Auditiva ${ }^{9}$, fundamentam-se na perspectiva biomédica de inclusão do surdo na sociedade ouvinte, através da disponibilização de aparelhos auditivos dentre outras práticas de oralização.
Em contrapartida, na construção de uma reflexão contra-hegemônica a esse paradigma dominante, a partir da década de 1960, os chamados estudos culturais trouxeram à tona a discussão sobre o processo de construção cultural das identidades. A cultura e a linguagem, ou as formações discursivas presentes na sociedade, passaram a ter papel de destaque nesta teoria e as relações de poder foram consideradas presentes nas práticas culturais ${ }^{10}$. Neste referencial epistemológico, vários autores nacionais e internacionais do campo da educação, particularmente na educação de surdos, identificaram a existência de diversas comunidades surdas com representações e identidades diversificadas sobre a surdez no seio da sociedade. Defendem que essas identidades surdas, múltiplas e multifacetadas, dependem das vivências sociais de seus membros, propondo um discurso da surdez fundado na diferença cultural e linguística, como seria o caso do uso da língua de sinais na socialização dos surdos ${ }^{11-16}$.

Dado a preponderância de estudos biomédicos sobre o assunto da surdez no campo da saúde e a lacuna na literatura representada por estudos sobre o tema, na perspectiva aqui pretendida, objetivamos compreender as representações de uma comunidade de surdos usuários da língua de sinais sobre sua própria surdez e sobre as intervenções em saúde que lhes são dirigidas, no contexto de sua imersão no paradigma biomédico e das políticas públicas nele referenciadas.

\section{Método}

A pesquisa fundamentou-se no enfoque teóricometodológico da pesquisa qualitativa em saúde, na vertente crítico-interpretativa, que considera o conhecimento como a resultante de uma dialética entre o sujeito epistêmico e o fenômeno em estudo, reconhecendo a centralidade dos processos simbólicos e sua vinculação à materialidade da existência ${ }^{17}$. Entendemos que a escolha do enfoque qualitativo decorre da natureza do objeto em questão, haja vista o mesmo dizer respeito aos significados que os surdos participantes da investigação atribuem à própria surdez e sua relação com as intervenções em saúde.

Escolhemos como campo de pesquisa, no qual se deu a seleção de participantes, uma instituição pública estadual de referência para o ensino especial para surdos no Estado do Ceará, localizada em Fortaleza, onde se adota para comunicação dos alunos surdos a Língua Brasileira de Sinais - Libras. Instituições desse tipo constituem- 
se como uma rede nacional de educação especial para surdos. Configurou-se, desse modo, uma amostra teórica, tal como formulada por Schwand $\mathrm{t}^{18}$, na qual os participantes foram escolhidos por sua relevância para a questão da pesquisa. Utilizamos também a saturação teóri$\mathrm{ca}^{19} \mathrm{em}$ relação ao número de participantes da pesquisa, entendendo-a não como esgotamento absoluto do exercício hermenêutico, sempre inacabado, mas um ponto no qual o acúmulo subjetivo em relação ao problema focalizado já possibilitava a compreensão do objeto pesquisado, nos limites vislumbrados pelo estudo.

Para obtenção do material empírico, foi utilizada a técnica do grupo focal, posto que, para além do que possibilitam as técnicas individuais, propicia a valorização da comunicação e interação grupal, a fim de produzir dados e insights ${ }^{20,21}$. Nesse sentido, os participantes foram estimulados a se comunicar uns com os outros, a comentar experiências, a apontar diferentes perspectivas relacionadas à surdez em sua história de vida e em relação às intervenções de saúde. Foram realizados três encontros de uma hora e meia cada na própria instituição, durante o ano de 2010. Participaram da condução das discussões em grupo: a) um moderador, membro da equipe de pesquisa, que realizou uma imersão no campo durante seis meses e tinha noções básicas de Libras; b) um intérprete profissional de Libras, responsável pela realização da tradução simultânea dessa língua de sinais para o português falado, de modo a possibilitar a gravação em áudio dessa tradução para posterior transcrição; c) e um observador de apoio.

Participaram das três sessões do grupo focal nove professores de Libras surdos, todos inseridos nas atividades docentes dessa instituição de ensino especial, entendendo-se, portanto, que tal especificidade pode demarcar um ethos no grupo que participou desse estudo. Os participantes apresentavam surdez profunda, nenhum usava aparelho auditivo, embora a maioria mencionasse experiências com diferentes tipos de aparelhos auditivos no passado. Todos afirmaram comunicar-se no dia-a-dia somente pela Libras.

Após a realização dos grupos focais, os relatos foram transcritos e o material empírico submetido à leitura flutuante para impregnação do sentido das falas. Nesta fase, houve a identificação de temas centrais, categorias analíticas e categorias empíricas que compuseram a rede de significados da nossa pesquisa ${ }^{22}$. A análise do material orientou-se, conforme já aludido, pela vertente crítica-interpretativa visando a apreen- der os significados construídos pelos surdos, considerando sua historicidade, reconhecendo que o universal sempre é pensado dentro das possibilidades de uma dada linguagem ${ }^{23}$. Este círculo hermenêutico possibilitou aos pesquisadores, sem qualquer contato anterior com a comunidade surda estudada, um processo de reflexividade diante do seu saber, visto que, não raro, evidenciaram-se no discurso do grupo percepções distintas entre os membros da equipe de pesquisa e os surdos em relação às representações sobre surdez.

Tendo em vista o espaço editorial disponível, selecionamos para discussão três categorias julgadas mais relevantes para o objetivo do presente trabalho: a) Identidade e Cultura Surda; b) Discurso do deficiente versus discurso do surdo: uso de tecnologias auditivas; c) Ética do Cuidado e Políticas Públicas: o papel da escolha.

A pesquisa foi aprovada pelo Comitê de Ética em Pesquisa da Universidade Federal do CearáCOMEPE, de acordo com a Resolução no 196/96.

\section{Resultados e Discussão}

\section{Identidade e Cultura Surda}

Historicamente, a concepção de mundo constitutiva do paradigma cultural da modernidade, reificando a ciência e as concepções ou práticas nela fundamentadas, e estabelecendo a supremacia do saber técnico-especializado sobre as demais formas de saber ou de experiências humanas, inclusive sobre si mesmo, criou as condições para a hegemonia de uma filosofia oralista na abordagem educacional ou terapêutica sobre os surdos, e na modulação da identidade surda pela ótica dos ouvintes, ou normais, na perspectiva biomédica.

A denominada filosofia oralista ou oralismo constitui-se uma concepção metodológica que defende a integração do surdo à sociedade por meio do treino intenso da fala e da leitura labial (oralização) e do treino auditivo. Acredita que o surdo só poderia aprender, desenvolver-se intelectual e linguisticamente, através da língua oral ${ }^{24}$. Tais concepções adquirem caráter impositivo, negando e proibindo a língua de sinais, utilizando até mesmo práticas de castigo corporal para essa aprendizagem. O Congresso de Milão (1880), composto pelos especialistas da época e por uma pequena representação de surdos, pode ser entendido como um marco histórico da consolidação dessa perspectiva epistemológica de aborda- 
gem na educação de surdos, de sua socialização e da constituição de sua identidade. Foi então estabelecida como norma a superioridade da fala em detrimento de outras formas de comunicação do surdo, como a língua de sinais, conforme revelam as resoluções aprovadas, citada na obra de Skliar ${ }^{8}$ :

I - Considerando la indudable superioridad de la palabra sobre los gestos para restituir al sordomudo a la lengua, el Congreso declara que el método oral debe ser preferido al de la mímica para la educación e instrucción de los sordomudos; II Considerando que el uso simultáneo de la palabra $y$ de lo gestos mímicos tiene la desventaja de dañar la palabra, la lectura sobre los labios y la precisión de las ideas, el Congreso declara que o método oral debe ser preferido [...]

No nosso estudo, observamos que, de fato, o conceito relativo à noção de identidade surda, em contraposição a uma identidade ouvinte, ambas culturalmente construídas, emergiu como uma categoria central para compreendermos os significados atribuídos à surdez pela própria comunidade surda estudada, bem como as ações de políticas públicas julgadas importantes para o cotidiano do surdo. Evidenciou-se um discurso baseado na diferença cultural e linguística que perpassa pela identidade do surdo, em contraposição ao ouvinte. Ser surdo, nesse contexto, significa acessar o mundo essencialmente pela experiência visual. A vivência visual da naturezamundo constitui seu modo de ser e uma característica fundamental da identidade do surdo, nesta perspectiva:

[...] o surdo tem percepção apenas visual, tudo o que ele faz é uma percepção visual, essa identidade está dentro da cultura e tem as suas características próprias. [...] Quando nós estamos dirigindo, nós temos a percepção visual muito mais aguçada do que a dos ouvintes [...] é uma característica da minha identidade, a percepção visual. (Surdo 2).

[...] tem ouvinte que sabe Libras perfeito e tem perda de audição [...] esse daí que vai perdendo a audição vai ser surdo, vai acabar entrando na identidade surda [...] vai entrar na cultura surda numa boa, não vai sentir diferença. [...] A pessoa vai ter a linguagem [...] aprendendo a Libras e na comunidade, aí vai ser surdo. (Surdo1)

Neste aspecto, a experiência física da perda de audição torna-se secundária na representação da surdez. Assim, a surdez não é conceituada nesse grupo pela ausência do sentido da audição ou como deficiência. Ancora-se em componentes culturais e linguísticos, ou seja, a pessoa é considerada surda porque compartilha experiências comuns no universo da comunidade surda percepção e comunicação visual (língua de sinais) - e não porque tem perda de audição. Percebe-se como possuidor de uma identidade surda, presente em uma cultura que se diferencia de outras. Identidade, cultura e a língua de sinais constituem, no olhar desses surdos, uma unidade definidora da surdez; ser surdo passa a ser uma questão antes de identidade do que biológica.

Uma identidade é construída e compartilhada socialmente no interior de uma cultura, dos discursos produzidos, nas representações compartilhadas e nos significados atribuídos. É no contexto dos Estudos Culturais que situamos o termo Identidade Surda. No Brasil, os Estudos Culturais têm influenciado um campo de pesquisa voltado à educação do surdo, inscrito em um paradigma denominado de Estudos Surdos. Buscam compreender as práticas sociais e identitárias do surdo voltadas à diferença cultural e linguística, contra a interpretação de surdez como deficiência, doença, experiência da falta e medicalização ${ }^{11-13}$.

Parafraseando Sá ${ }^{12}$ e Perlin ${ }^{14}$ podemos afirmar que os informantes-chave de nossa pesquisa consideram-se surdos em relação à experiência visual, longe da experiência ouvinte. O uso da comunicação visual, neste contexto, é a evidência básica para pertencer ao grupo dentro da comunidade identificada, tendo pouca importância o grau da perda de audição.

Perlin ${ }^{14}$ considera como primordial para a constituição das identidades surdas o convívio do surdo com a comunidade surda. Acredita que, estando nessa comunidade, outras experiências diferentes daquelas voltadas à incapacidade de ouvir serão compartilhadas, propiciando aos surdos a possibilidade de se representar como sujeitos capazes e culturais; e que é no encontro do surdo com o seu semelhante que a formação ou a transição das identidades surdas acontecem:

"a construção da identidade dependerá, entre outras coisas, de como o sujeito é interpelado pelo meio em que vive. Um surdo que vive junto a ouvintes que consideram a surdez uma deficiência que deve ser tratada pode constituir uma identidade referenciada nesta ótica. Mas um surdo que vive na comunidade possui outras narrativas para contar a sua diferença e constituir sua identidade" 14 .

Percebemos que o encontro do surdo com outros surdos, em contato com a comunicação visual, desvelou a possibilidade de ser surdo a partir da sua experiência visual, gerando a sensação de pertencimento, de identificação, de encan- 
tamento e de estar no mundo, de tornar-se um ser social que interage pela comunicação, pela língua, que se pode fazer entender e ser entendido pelos pares:

[...] o meu negócio mesmo era brincar de bola, sair, me divertir e não tinha preocupação nenhuma, até eu encontrar essa escola. [...] Tinha muito surdos. Eu fiquei feliz. O pessoal me chamava: vamos, vamos, vem cá, tu é surdo, vamos aqui. Conversavam comigo, me levavam ao shopping, e me mostraram a escola. Quando eu entrei (na escola) todo mundo se comunicando em Libras, o primeiro impacto que eu tive com a Libras e com as pessoas falando com as mãos, eu me senti outra pessoa. Foi diferente. (Surdo 5)

[...] eu fiz uma troca, a oralização pela Libras, então eu fiquei muito feliz. Gostei e me identifiquei bastante com a Libras. Fui evoluindo [...] me senti mais valorizado [...] Percebi a comparação da minha vida de hoje e a minha vida passada. Hoje, sou mais feliz [...] você se sente muito mais a vontade com a comunidade surda. São todos ingressando no mesmo caminho, no mesmo objetivo, a questão da consciência, da identidade surda, da cultura surda é muito importante, eu me sinto feliz [...] eu procurei valorizar a Libras, eu valorizei, então assim, isso é uma cultura, é uma identidade mesmo, você valorizar a sua própria língua, é a lingua que eu falo, que eu gosto, que me comunico. (Surdo 6)

Representações semelhantes foram recorrentes na história de vida dos surdos participantes da pesquisa. A aproximação com a comunidade surda e com a língua de sinais, na escola (realidade da minoria) ou na associação de surdos (realidade da maioria), representou um momento único, crucial e de ruptura na história de vida dessas pessoas, ao conhecerem outros surdos com as mesmas dificuldades - de escolarização e de comunicação -, com experiências comuns - o uso da prótese auditiva, conflito familiar e o preconceito - e com os mesmos objetivos de vida. Construíram-se então as condições identitárias e culturais para a militância surda como uma categoria fundamental do ser surdo, nesta perspectiva.

$\mathrm{Na}$ comunidade surda, em convivência com o movimento surdo, a representação da surdez como deficiência distancia-se da pessoa surda; ao ser conhecedor de sua diferença, a identidade surda consolida-se, tornando forte sua militância social ${ }^{11}$. De acordo com os autores dos Estudos Surdos, essa militância é conhecida como política da identidade surda, retratando a luta do surdo pelo surdo, a favor do estilo de vida surda. O movimento surdo nutre essa política, ou seja, nutre o sentir-se surdo, o ser surdo cultural e político ${ }^{14}$.

Entretanto, ainda segundo Perlin ${ }^{14}$, ela mesma surda, as identidades surdas não são homogêneas e podem apresentar-se segundo diferentes conformações de representações. A partir de sua história de vida e da história de vida de membros de comunidades surdas, ela classificou os surdos em pelo menos seis categorias de identidades, assim caracterizadas:

“[... 1) No grupo onde entram os surdos que fazem uso de comunicação visual se dá uma representação de identidades surdas. Noto formas muito diversificadas de usar a comunicação visual. No entanto, o uso de comunicação visual caracteriza o grupo [...] 2) Um outro tipo de identificação é a que denomino: identidades surdas híbridas. Elas se fazem presentes entre os surdos que nasceram ouvintes, e que com o tempo se tornaram surdos [...] 3) Uma outra possibilidade de identificação são as identidades de transição. [...] Transição é o aspecto do momento do encontro e passagem do mundo ouvinte com representação da identidade ouvinte para identidade surda [... 4) Muitos surdos vivem sob uma ideologia latente que trabalha para socializar os surdos de maneira compatível com a cultura dominante. A hegemonia dos ouvintes exerce uma rede de poderes difícil de ser quebrada pelos surdos, que não conseguem se organizar em comunidades para resistirem ao poder. Aí pode dar início ao que chamo de 'identidade surda incompleta'. [... 5) Suponho uma outra identidade, outro tipo de representação, quando o surdo nega a identidade surda. Esse caso é de uma identidade surda 'reprimida' seja porque evitada, negada, escondida, porque ridicularizada, ou porque premida pelo estereótipo [... 6) 6...]' identidades flutuantes'... estão presentes onde os surdos vivem e se manifestam a partir da hegemonia dos ouvintes. [...] Existem alguns surdos que querem ser ouvintizados a todo custo [...]".

A compreensão da diversidade de tais identidades e representações sobre a surdez ajudará a problematizar as complexidades dos discursos e das práticas inerentes ao campo da saúde, como o faremos a seguir.

\section{b) Discurso do deficiente versus discurso do surdo: uso de tecnologias auditivas}

A preocupação exclusiva com o aspecto fisiológico da surdez gera uma prática de utilização de tecnologias (como aparelhos auditivos ou implante coclear) focadas na adaptação do de- 
ficiente auditivo à sociedade, onde se busca um enquadre aos padrões de normalidade. Tal modelo de intervenção, de bases epistemológicas e paradigmáticas historicamente construídas na racionalidade das ciências naturais, se sustenta no modelo da biomedicina, reproduzido no plano discursivo e da práxis, por grande parte dos profissionais da área da saúde ${ }^{25}$.

O foco na doença, neste caso classificada como deficiência auditiva, legitima o uso do poder disciplinar ${ }^{26}$ para impor regras aos corpos dos indivíduos, em detrimento do processo vivenciado e dos sentidos conferidos ao sujeito surdo que utiliza as diversas tecnologias. Particularmente, a supervalorização, pelos especialistas e pela mídia, de tecnologias cada vez mais sofisticadas para obter uma saúde idealizada, subtrai a dimensão humana e a experiência subjetiva presentes nos significados produzidos sobre a enfermidade.

O saber cientifico ideologizado, aqui materializado nas tecnologias preconizadas para o surdo, quando empregado sob a égide do projeto normalizador que negligencia (ou oculta) relações de poder envolvidas na sua produção e dos processos de significações que os permeia, gera uma dessimetria perceptiva entre os profissionais que empregam a técnica, os familiares e os usuários surdos a quem são destinadas as ações. Um discurso sobre os significados atribuídos à surdez, oposto ao modelo biomédico da deficiência, evidencia-se na comunidade surda estudada quando se expressa sobre os aparelhos auditivos e sobre o implante coclear, no caso deste último a partir de um contexto de grande divulgação midiática sobre essa nova tecnologia, à época:

A gente joga fora o aparelho porque faz muito barulho. A gente fica nervoso por conta daquilo. $O$ meu está guardado. Desculpa, mas eu não consigo usar, pois não me sinto bem com ele. Você não escuta a voz com o aparelho, apenas o aumento de barulho, os estalos das coisas, as pancadas na nossa cabeça, só isso. As pessoas acham que eu fico feliz por causa do aparelho, mas não. Muitas famílias obrigam, não querem Libras e querem que você use aparelho e que você consiga entender, e não dá. Eu já falei... eu não consigo ouvir! (Surdo 2)

[...] para quê colocar esse implante? Muitas vezes, isso é imposto pela sociedade, pela mídia, que tem que ser colocado. Eu tenho que usar isso aqui para eu ser igual aos ouvintes? Eu tenho que viver no meu mundo, eu tenho o meu mundo, eu tenho a minha pessoa, o meu jeito. [...] Eu só vou ser aceito pela sociedade se eu colocar esse implante? (Surdo 3)

Os surdos apresentam outra percepção sobre a surdez e as tecnologias a eles destinadas, oposta à normatividade técnica, às expectativas familiares e às políticas públicas moldadas pela mesma normatividade. Tal dessimetria perceptiva entre usuários surdos, profissionais e ações governamentais se apresenta, visto que suas perspectivas baseiam-se em premissas diferenciadas. A concepção técnico-política-profissional, ancorada na perspectiva do déficit, afirma que a surdez é uma deficiência auditiva, conferindo às tecnologias uma estratégia para adaptá-lo e normatizá-lo à sociedade ouvinte. Por outra via, o surdo percebe a surdez enquanto identidade, lutando por reconhecimento, e não por adaptação.

Apesar da representação negativa do aparelho auditivo e do implante coclear neste grupo da comunidade surda, não se pretende aqui adjudicar-se aos dualismos saber científico/saber popular ou objetividade/subjetividade, mas encontrar estratégias de aproximação entre os mesmos a fim de vivenciar a plenitude de suas contradições, para que o uso das tecnologias de saúde não permaneça indefinidamente sem uma revisão ética e crítica. Tal revisão implica em considerar esse uso como uma escolha que deve se processar com base na autonomia e no respeito à alteridade.

Desse modo, para que se possa utilizar as tecnologias disponíveis pelos profissionais de saúde e pelas políticas públicas, é necessário compreender o fenômeno da surdez na transição de suas diferentes concepções, constituídas por paradigmas paradoxais, tais como: (1) a deficiência auditiva patologizada, construída sob a égide do saber científico de ouvintes e (2) o surdo inserido no discurso da diferença linguística e cultu$\mathrm{ral}^{27}$. A introjeção, consciente ou não, de um desses aspectos por agentes técnicos (profissionais) ou político-sociais (gestores) da saúde, implica invariavelmente em um manejo diferenciado na utilização dos aparatos tecnológicos.

\section{c) Ética do Cuidado e Políticas Públicas: o papel da escolha}

Merhy ${ }^{28}$ atenta que, para além da técnica, podem surgir demandas por dispositivos tecnológicos mais sensíveis às necessidades de saúde de sujeitos e coletividades no encontro assistencial. $\mathrm{O}$ autor defende, portanto, um exercício micropolítico de compreensão contra-hegemônica das práticas de saúde ao incluir o aspecto relacional profissional-usuário enquanto uma tecnologia leve de cuidado.

Entretanto, as práticas de intervenção sobre a surdez e as políticas correspondentes, neste contexto, ainda se apresentam como o que esse autor nomeia tecnologia dura, a qual se funda- 
menta no emprego de instrumentos centrados na intervenção objetiva, gerando uma imposição valorativa de uma maioria ouvinte sobre uma minoria surda.

Entendemos que, ao contrário da imposição, a suposta cura se estabelece no encontro relacional entre serviço-profissional-usuário, onde ela só é possível na medida em que o usuário permite e adere às ações programáticas-tratamentos oferecidas pelo serviço-profissional de saúde. Nesse sentido, a preocupação com o processo na utilização de tecnologias e a adoção de novas inteligibilidades na compreensão da deficiência auditiva faz-se necessária, visto que a surdez, na perspectiva do surdo, não se configura apenas como uma diferença fisiológica auditiva, mas como uma tessitura de ordem identitária e cultural, de outra ordem de complexidade.

Assim, o problema instaurado não seria entrar em critérios técnicos de eficácia, ou mesmo morais de ética político-profissional, para responder se o uso de tecnologias restauradoras se justifica por si. A questão basilar seria: quais as potentes estratégias político-técnicas e relacionais que os serviços-profissionais de saúde podem empregar na utilização de tecnologias para que haja uma aproximação das distintas percepções, reconhecendo o caráter subjetivo e cultural da surdez?

Para esta pergunta, apontamos que o eixo central de qualquer intervenção localiza-se no cuidado, e não na cura como preconiza a biomedicina. O cuidado em saúde é essencialmente, uma estratégia relacional que permite uma compreensão ampliada e integrada, na qual a (re) construção contínua e simultânea dos projetos de vida dos usuários se materializa nas práticas de saúde ${ }^{29}$.

O cuidado ético reconhece a alteridade do surdo a partir de um contato genuíno entre serviço-profissional e usuário, que constroem sentidos em sua relação, ou seja, no encontro ético de alteridades no espaço da produção do cuidado. Para o surdo, neste cuidado, é preciso respeitar a escolha do usuário na aderência ou não aos projetos terapêuticos propostos. Neste caso, o papel da escolha torna-se fundamental, mesmo quando se trata da controversa utilização de tecnologias duras na criança:

[...] tinha um surdo de dois anos que a família mandou fazer um implante. A criança não sabia o que era e foi crescendo, aí às vezes amolava muito aquele negócio, ai tirava e colocava, tirava e colocava. Só que dentro do cérebro fica aquele imã implantado e não tem como tirar. [...] Depois que ele cresceu, ficou sabendo que tinha aquilo e ele não sabia porque, aí ele brigou muito com a famí- lia. [...] O surdo foi no médico, mas ele disse: desculpa, mas não dá pra tirar, vai ter que viver com isso o resto da vida [...]. (Surdo 1)

Percebemos que a comunidade surda questiona a imposição tecnológica, mesmo na infância, visto que a criança ainda não imergiu na cultura surda e não tem autonomia para escolher. Mesmo tendo consciência que, em termos técnicos, a tecnologia utilizada apresenta melhores resultados quando implantada precocemente, o surdo precisa saber do que se trata nos seus benefícios e nos seus efeitos iatrogênicos para, então, tomar uma decisão definitiva.

Da mesma forma, em relação às Políticas Públicas voltadas ao surdo, defendem que, ao invés de o governo focalizar na recuperação da deficiência por meio aparatos tecnológicos, poderia alternativamente investir na educação de surdos através da Libras:

Cada um pode fazer o que quer. Aí, só porque os pais têm direitos sobre a criança, pega e coloca um implante naquela criança. [...] O aparelho custa quarenta mil e o governo está muito preocupado, mas esqueceu, por exemplo, que as escolas têm o bilinguismo, a metodologia de repassar valores, organizar e tudo. Então, o importante é a escola. O governo vai investir numa coisa, esquecendo que a educação seria mais necessária para a comunidade surda. (Surdo 1)

Diante de tais discursos, percebemos que é imprescindível articular as intervenções técnicas com outros fatores não tecnológicos. Como afirma Ayres" ${ }^{29}$ "nunca, quando assistimos à saúde de outras pessoas, mesmo estando na condição de profissionais, nossa presença na frente do outro se resume ao papel de simples aplicador de conhecimentos". A dimensão ética do cuidado que implica no reconhecimento da diferença, no respeito à escolha e na presença implicada do profissional pode estabelecer uma negociação simbólica no uso de tecnologias.

\section{Considerações Finais}

Coexistem diferentes concepções sobre surdez envolvendo dimensões fisiológicas, simbólicas e culturais na sociedade em geral, entre os profissionais de saúde e entre os surdos, em especial aqueles participantes da comunidade surda e mais vinculados aos movimentos surdos.

De forma mais polarizada, a concepção ancorada na perspectiva científico-mecanicista ou biomédica compreende a surdez como uma deficiência auditiva de caráter orgânico-fisiológico, 
conferindo às tecnologias oralizantes ou auditivas-reparadoras o papel de estratégia fundamental para adaptá-los e integrá-los à sociedade.

Por outro lado, a concepção cultural compreende a surdez no marco referencial da identidade, lutando por um espaço existencial de diferença fundamentado em vivências visuais de socialização, avessa, portanto, à adaptação social própria da normatividade hegemônica nas políticas e práticas de saúde.

A compreensão destes distintos aspectos torna-se necessária na medida em que pode proporcionar mudanças no modo como os serviços-profissionais de saúde e a sociedade de ouvintes percebem e se relacionam com os surdos.

Não se trata, portanto, de negar os avanços científicos e tecnológicos, mas compreender que as ações em saúde não se reduzem à imposição de tecnologias sobre o outro para obter um resultado de retorno à normalidade hegemônica, esta também socialmente construída. Torna-se imperativo incluir os atores envolvidos na produção e no consumo das práticas da saúde, bem como seus valores e sua subjetividade, e, dessa forma, diminuir as angústias, os "medos", as dúvidas e os desconhecimentos que pairam sobre esse (des) encontro no cuidado e nas políticas em saúde.

\section{Colaboradores}

JD Nóbrega, AB Andrade, RJS Pontes, MLM Bosi e MMT Machado participaram igualmente de todas as etapas de elaboração do manuscrito.

\section{Agradecimentos}

À Coordenação de Aperfeiçoamento de Pessoal de Nível Superior (CAPES) pela concessão de bolsa de Mestrado à aluna Juliana Donato Nóbrega e ao professor Ricardo José Soares Pontes pela orientação da presente pesquisa. 


\section{Referências}

1. Gatjens LFA. Entrevista. [artigo da Internet]. 2009 jan 30 [acessado 2009 maio 31]. Disponível em: http://www.planetaeducação.com.br/novo/ artigo.asp? artigo $=1385$

2. Moura MC. O Surdo: caminhos pra uma nova identidade. Rio de janeiro: Revinter; 2000

3. Silva V. Educação de surdos: uma releitura da primeira escola pública para surdos em Paris e Congresso de Milão em 1880. In: Quadros RM, organizador. Estudos Surdos I. Petrópolis, Rio de Janeiro: Arara Azul; 2006. p.14-37.

4. Plaisance E. Denominações da infância: do normal ao patológico. Educ. Soc. 2005; 26(2):405-417.

5. Thomas AS da. Entre normais e anormais: invenções que tecem inclusões e exclusões das alteridades deficientes. In: Pellanda NMC, Schlunzen E, Schlunzen K, organizadores. Inclusão Digital: tecendo redes afetivas/cognitivas. Rio de Janeiro: DP\&A; 2005.

6. Sassaki RK. Como chamar as pessoas que têm deficiência? Revista da Sociedade Brasileira de Ostomizados 2003; 1(1):8-11.

7. Sassaki RK. Terminologia sobre deficiência na era da inclusão. Revista Nacional de Reabilitação 2002; 5(24):6-9.

8. Skliar C. La educación de los sordos: una reconstruccion histórica, cognitiva y pedagógica. Mendoza: EDIUNC; 1997.

9. Brasil. Ministério da Saúde (MS). Secretária de Atenção à Saúde. Departamento de Ações Programáticas Estratégicas. Manual de legislação em saúde da pessoa com deficiência. 2a ed. Brasília (DF): Editora do Ministério da Saúde; 2006.

10. Hall S. The centrality of culture: notes on the cultural revolutions of our time. In: Thompson $\mathrm{K}$, organizador. Media and cultural regulation. London, New Delhi: Thousand Oaks, The Open University, SAGE Publications; 1997.

11. Strobel KL. Surdos: os vestígios culturais não registrados na história [tese]. Florianópolis (SC): Universidade Federal de Santa Catarina; 2008.

12. Sá NL de. Os Estudos Surdos. In: Sá NL de, organizador. Cultura, poder e educação de surdos. São Paulo: Paulinas; 2006.

13. Skliar C, organizador. Educação e Exclusão: abordagens sócio-antropológicas em Educação Especial. Porto Alegre: Mediação; 2006. 112p

14. Perlin G. Histórias de vida surda: identidades em questão [tese]. Porto Alegre (RS): Universidade Federal do Rio Grande do Sul; 1998.

15. Wrigley O. The politics of deafness. Washigton: Gallaudet University Press; 1996.

16. Lane H. The medicalização of cultural deafness in historical perspective. In: Fisher R, Lane H. The looking back: a reader on the history of deaf communities and their sign languages. Hamburg: Signum-Verlag; 1993.
17. Bosi M, Mercado F, organizadores. Avaliação qualitativa de programas de saúde: enfoques emergentes. Petrópolis: Vozes; 2006.

18. Schwandt $\mathrm{T}$. The sage dictionary of qualitative inquiry. Los Angeles: Sage Publications Inc.; 2007.

19. Fontanella B, Ricas J, Turato E. Amostragem por saturação em pesquisas qualitativas em saúde: contribuições teóricas. Cad Saude Publica 2008; 24(1):17-27.

20. Minayo MC. O desafio do conhecimento: pesquisa qualitativa em saúde. $11^{\text {a }}$ ed. São Paulo: Hucitec/ Abrasco; 2008.

21. Pope C, Mays N. Pesquisa qualitativa a atenção à saúde. Porto Alegre: Artmed; 2009.

22. Nóbrega JD. O Mundo dos Surdos: representações, cotidiano e políticas públicas [dissertação]. Fortaleza (CE): Universidade Federal do Ceará; 2010.

23. Schleiermacher F. Hermenêutica: arte e técnica da interpretação. Bragança Paulista: Editora Universitária São Francisco; 2003.

24. Pires EM. O Sucesso Escolar de Alunos com Surdez Neurossensorial Severo/Profunda: A Educação em Tempos de Inclusão/ Exclusão [tese]. Goiânia (GO): Universidade Católica de Goiás; 2008.

25. Guimarães CF, Meneghel SN. Subjetividade e saúde coletiva: produção de discursos na re-significação do processo saúde-doença no pós-moderno. Rev. Mal-Estar Subj. 2003; 3(2):353-371.

26. Foucault M. Vigiar e punir. Petrópolis: Vozes; 1983.

27. Skliar C. Um olhar sobre o nosso olhar acerca da surdez e das diferenças. In: Skliar C. A surdez: um olhar sobre as diferenças. Porto Alegre: Editora Mediação; 1998. p. 7-32

28. Merhy E. Um dos grandes desafios para os gestores do SUS: apostar em novos modos de fabricar os modelos de atenção. In: Merhy E, Miranda H, Rimoli J, Franco T, Bueno W, organizadores. O trabalho em saúde: olhando e experienciando o SUS no cotidiano. $3^{\text {a }}$ ed. São Paulo: Hucitec; 2006.

29. Ayres J. Cuidado e reconstrução das práticas de saúde. Interface Comun Saúde Educ 2004; 8(14):73-92.

Apresentado em 30/11/2011

Aprovado em 05/12/2011

Versão final apresentada em 16/12/2011 